Revue

Revue de l'histoire des religions

de Ihistoire des religions

1 | 2018

Varia

Francesca PRESCENDI, Rois éphémères. Enquête sur le sacrifice humain

Genève, Labor et Fides, 2015

Thomas Galoppin

\title{
CpenEdition
}

Journals

Édition électronique

URL : http://journals.openedition.org/rhr/8857

DOI : 10.4000/rhr.8857

ISSN : 2105-2573

Éditeur

Armand Colin

Édition imprimée

Date de publication : 1 mars 2018

Pagination : 152-155

ISBN : 978-2-200-93166-7

ISSN : 0035-1423

Référence électronique

Thomas Galoppin, «Francesca Prescend, Rois éphémères. Enquête sur le sacrifice humain », Revue de I'histoire des religions [En ligne], 1 | 2018, mis en ligne le 20 mars 2018, consulté le 13 janvier 2021.

URL : http://journals.openedition.org/rhr/8857 ; DOI : https://doi.org/10.4000/rhr.8857

Ce document a été généré automatiquement le 13 janvier 2021.

Tous droits réservés 


\title{
Francesca PRESCENDI, Rois éphémères. Enquête sur le sacrifice humain
}

\author{
Genève, Labor et Fides, 2015
}

\section{Thomas Galoppin}

\section{RÉFÉRENCE}

Francesca PRESCENDI, Rois éphémères. Enquête sur le sacrifice humain, Genève, Labor et Fides, 2015, 12,5 cm, 198 p., $21 €$, ISBN 978-2-8309-1500-6.

Dans la préface de ces Rois éphémères, F. Prescendi dédie son livre aux «lecteurs capables de pratiquer un zapping stimulant entre différentes époques et divers mondes culturels », c'est-à-dire surtout entre les savants du xxe siècle et les textes de l'époque impériale romaine. Son enquête entre passé proche et passé lointain porte sur la notion et l'histoire des sacrifices humains, et s'articule en quatre chapitres. L'ensemble est enrichi de huit illustrations en noir et blanc dans le corps du texte et dix figures en couleurs dans le hors-texte.

2 Le premier chapitre («Le Père Noël, Lévi-Strauss et le roi des Saturnales ») introduit la problématique du comparatisme. Le point de départ de l'enquête est un article de C. Lévi-Strauss (1952), publié en réaction contre l'idée selon laquelle le Père Noël, brûlé en effigie par des paroissiens de Dijon en décembre 1951, était une nouveauté absolue. Pour identifier au contraire dans le Père Noël une «nouvelle manière de reformuler un substrat symbolique traditionnel », l'anthropologue mettait en série, à travers le temps, des figures masculines ou « rois » d'une inversion temporaire de l'ordre social, toutes articulées à une fin de cycle annuel, souverains d'autant plus éphémères qu'ils sont rituellement mis à mort. Or, parmi les précurseurs du Père Noël "assassiné » en décembre 1951, C. Lévi-Strauss comptait le roi des Saturnales. Ces dernières sont une fête romaine à l'occasion de laquelle les Romains et leurs esclaves jouaient une inversion sociale avec un « roi » pour maitre de banquet. Un mythe d'origine de la fête évoquait des sacrifices humains abolis par Hercule, mais le rapport entre Saturne et des 
sacrifices humains pourrait venir de son identification, à partir du III $^{\mathrm{e}}$ siècle avant notre ère au moins, au Cronos grec et au Baal-Hammon punique, réputés dévoreurs d'enfants (dans le mythe hésiodique pour l'un, dans les rituels attribués aux Phéniciens par la littérature grecque et latine pour l'autre). Mais le sacrifice du roi des Saturnales n'a guère laissé de trace et la problématique de F. Prescendi, en tant que romaniste, est dès lors celle de l'historicité des relations entre "sacrifice humain» et Saturnales. Toutefois, sa méthode est d'abord historiographique : à l'appui des survivances que C. Lévi-Strauss sollicitait pour expliquer des traditions de Noël - et qui trouvent encore presse à chaque solstice d'hiver - se trouvaient en effet les théories évolutionnistes du Rameau d'or (1906-1915) dans lequel J. G. Frazer présentait le roi des Saturnales comme une personnification du dieu agraire mis à mort pour un effet de «magie sympathique $»$.

3 Les chapitres 2 ("Saint Dasius et les sacrifices humains : un débat entre savants ») et 3 ("Cumont, Frazer et Lang s'écrivent à propos de saint Dasius») reviennent sur la correspondance entre anthropologues et historiens à propos d'un texte peu connu, les Actes de saint Dasius, dans lequel F. Cumont, et à sa suite J. G. Frazer, voient un cas de sacrifice humain. Pour F. Cumont en effet, d'après de "(minces) analogies » entre différents témoignages antiques, c'est l'influence de sacrifices humains orientaux qui aurait revivifié dans l'armée romaine, en proie à un climat de "cruauté ", des rites romains anciens, à l'image de la deuotio. A. Lang, en revanche, très critique à l'égard de J. G. Frazer, n'accepte pas cette idée, considérant que Dasius a été exécuté pour refus de sacrifier aux empereurs et que les Saturnales ont été ajoutées au récit de sa passion. La correspondance entre les savants témoigne alors de l'autorité scientifique exercée par l'historien belge et de son arbitrage entre les anthropologues écossais.

4 Pourtant, l'argument des Actes est fragile et le chapitre 4 («Retour aux sources») revient sur les différents témoignages antiques invoqués pour (re)construire cette historicité des sacrifices humains. Il faut attendre ce chapitre pour lire une traduction des Actes. Le texte grec a été écrit entre 325 et 579 et relate le martyre à Durostorum (Mésie), le 20 novembre 303, du soldat romain et chrétien Dasius. Ce dernier, choisi pour être roi des Saturnales, refuse d'être sacrifié et est condamné à mort par le légat Bassus au terme d'un interrogatoire. F. Prescendi ne veut toutefois pas se prononcer sur ces Actes, laissant le débat ouvert sur deux hypothèses : soit il y a bien eu une pratique locale de sacrifice humain réel ou symbolique, soit le sacrifice humain a été ajouté au récit - seule la fête carnavalesque relevant alors de la réalité.

Il faut souligner le fait, toutefois, que tout commentaire part du postulat que les « fêtes de Cronos » du texte grec sont les Saturnales romaines, tout en assumant l'idée que celles-ci durent trente jours. Mais surtout, la lecture des Actes donne bien l'impression de deux parties : dans la première, Dasius est enfermé pour avoir refusé de se sacrifier à Cronos et préféré le martyre. Le vocabulaire sacrificiel est très net, même si on ajoutera que le couteau sacrificiel évoqué dans le $\$ 1$ est remplacé par une épée dans le discours de Dasius (\$4), une différence qui révèle, contre l'idée d'un rite bien identifié, une nuance dans les modalités d'énonciation de la mise à mort au profit d'une dramatisation. Dans la seconde partie (§ 6-12), Dasius est jugé par Bassus, sans qu’aucun d'eux n'évoque les fêtes de Cronos; le conflit est relatif aux hommages cultuels que Dasius est sommé d'adresser aux images des empereurs ( 8 7-9). En outre, Bassus offre deux heures à Dasius pour reconsidérer sa décision et choisir au contraire de "vivre avec nous dans la gloire » $(\$ 10)$. Comment un soldat supposé mourir sur l'autel vivrait- 
il avec ses pairs dans la gloire ? Cette gloire n'est-elle pas celle du soldat au service des empereurs triomphants, que la rhétorique hagiographique oppose à la gloire post mortem du martyr? N'a-t-elle pas été en partie masquée par l'évocation de la mort la plus « païenne » qui soit, le sacrifice humain (cf. James Rives, « Human Sacrifice among Pagans and Christians ", JRS, 85, 1995, p. 65-85)?

Les rituels antiques mis en série dans les échanges entre savants sont repris par F. Prescendi qui montre bien qu'il s'agit, en réalité, de différents types de mises à mort rituelles. Le faux roi tué lors des Sacées - une représentation grecque de rituels mésopotamiens - recouvre un "substitut » mis à mort en détournant la menace qui pèse sur le souverain véritable. Les pharmakoi évoqués sont mis à mort dans le cadre de rituels de purification, mais peut-on parler de « sacrifice » quand ils ne sont pas offerts à une divinité ? La seule explicitation du fait de "sacrifier un homme " (anthropothuein) est la note ethnographique de Strabon sur les Albanoi. Il faut noter en outre que le témoignage de Plutarque sur l'expulsion de Boulimos en Béotie (p. 141) ne donne pas la preuve d'un "transfert» de la souillure sur le pharmakos, mais seulement d'une procédure analogique proche des incantations de type pheugê. En revanche, plus proches des Actes sont les cas de deuotio romaine, militaire et attachée au salut de l'empereur. Mais il n'y a pas de lien entre deuotio et Saturnales, et si on identifie le sacrifice auquel se refuse Dasius à une deuotio, c'est donc le motif des fêtes de Cronos qui a été brodé dessus, peut-être à cause d'une association entre les Saturnales et les munera de décembre.

7 La question de l'historienne ne trouve finalement pas de réponse claire et définitive. F. Prescendi a prévenu qu'elle ne cherchait pas l'explication, mais l'observation. Cette série d'observations a cependant pour effet de montrer que la catégorie de «sacrifice humain » construite par les historiens et anthropologues il y a un siècle recouvre trop de mises à mort rituelles différentes pour ne pas être reconsidérée en fonction des modes d'énonciation des pratiques et de leurs enjeux interculturels (cf. Stella Georgoudi, "Le sacrifice humain dans tous ses états", Kernos, 28, 2015, p. 255-273). Les Rois éphémères ne révèlent pas tant un fait historique qu'un fait historiographique, dont la lecture peut être un départ pour penser de manière différente la ritualisation de la mise à mort des hommes.

\section{AUTEURS}

\section{THOMAS GALOPPIN}

PLH-Érasme, Université Toulouse - Jean Jaurès. 